\title{
What can we learn from a novel "Global Positioning System" in persistent atrial fibrillation?
}

Kenton J. Zehr, MD

From the Division of Cardiac Surgery, Department of Surgery, The Johns Hopkins Hospital, Baltimore, Md. Disclosures: Author has nothing to disclose with regard to commercial support.

Received for publication Aug 30, 2018; accepted for publication Aug 30, 2018; available ahead of print Oct 17. 2018

Address for reprints: Kenton J. Zehr, MD, Division of Cardiac Surgery, Department of Surgery, The Johns Hopkins Hospital, 1800 Orleans St, Zayed 7107, Baltimore, MD 21287 (E-mail: zehr@jhmi.edu).

J Thorac Cardiovasc Surg 2019;157:232-3

$0022-5223 / \$ 36.00$

Copyright (c) 2018 Published by Elsevier Inc. on behalf of The American Association for Thoracic Surgery https://doi.org/10.1016/j.jtcvs.2018.08.071

In this issue of the Journal, Ehrlich and colleagues ${ }^{1}$ introduce a new noninvasive technology to the surgical world. Electrophysiologists have validated this ECVUE system (Medtronic, Minneapolis, Minn) in patients to map atrial and ventricular dysrhythmias for more than 5 years. ${ }^{2}$ The article of Ehrlich and colleagues ${ }^{1}$ gives insight into to the surgical lesion set that is required to address persistent atrial fibrillation (AF) successfully. After all, if we are opening the chest, the freedom from AF must be high to claim a successful operation.

Faith in the mapping system can be gained by looking at the Global Positioning System (GPS). ${ }^{3}$ In the 1950s, the US Department of Defense found that tracking the position of satellites could be used to track fixed bodies on the surface of the earth. The Navstar GPS satellite constellation research project started in 1973 and launched the first 4 satellites in 1978. During the next several decades, integrated circuitry and mass production reduced the price of receivers to the $\$ 100$ range. GPS has 24 operational satellites orbiting $20,200 \mathrm{~km}$ above the surface of the earth in 6 different orbits. The satellites are spaced so that there are at least 4 available to a user any point on earth. With algorithms to correct for general relativity's time speed difference, the wobble of the earth's orbit, ionospheric and trophospheric wave speed differences, and signal refraction, the system has a potential for resolution down to less than an inch. Applications have been used to track people, animals, vehicles, weather balloons, and model rockets. GPS has particularly been used to understand how people interact with their environment, whether free-living activity, active transportation, or sport and recreation. ${ }^{4}$ After looking at this analogy, it is not a stretch to believe that placing a 252-electrode vest several inches from the heart and using gated computed tomographic scanning to establish atrial topography in relation to vest electrodes can allow accurate mapping of atrial dysrhythmias.

Ehrlich and colleagues ${ }^{1}$ mapped 10 patients with persistent AF requiring open-chest heart surgery for other cardiac

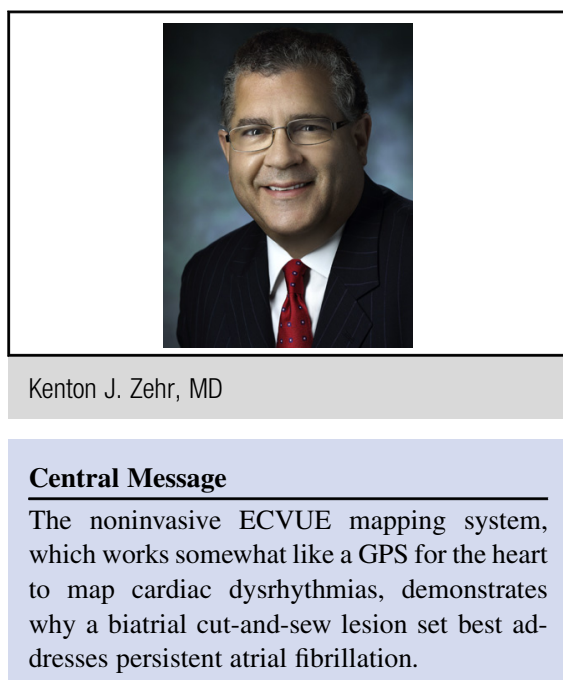

See Article page 248 . pathology. Mapping was rapid, requiring no more than 23 seconds. Mapping was successful in all patients. All subjects had biatrial pathology, and all had rotor activity in both atria. The number of rotors was highly variable, ranging from 18 to 92. All patients underwent a Cox-maze III or IV procedure, and 9 patients were discharged in sinus rhythm.

This article underscores several points that the literature bears out. Persistent AF is a biatrial disease. Catheter ablation's less than optimal long-term outcomes underscore this. Lim and associate ${ }^{5}$ used the ECVUE mapping system in 105 patients with a 20 second mapping acquisition. Persistence of AF was associated with increasing rotor and focal activity and increasing atrial regions beyond pulmonary vein areas. The right atrium was involved in nearly $50 \%$ of patients. The AFACART (Non-Invasive Mapping of Atrial Fibrillation) study ${ }^{6}$ used the ECVUE system to look at 118 patients with persistent AF in 8 European centers. ${ }^{6}$ On average, 4.9 driver sites were found per patient. The left atrium was involved in $53 \%$ of patients, the right atrium in $27 \%$, and the anterior interatrial groove in $20 \%$. In the catheter ablation world of persistent AF, increasing time spent in AF and complexity of AF translate to poor ablation results. In the study of Lim and associates, in the group that presented with sinus rhythm, there was a $91 \%$ termination of $\mathrm{AF}$; if the persistent $\mathrm{AF}$ was present less than 12 months, the rate was $69 \%$; and if AF was present for more than 12 months, the rate was $14 \%$. In the 
AFACART study, ${ }^{6}$ driver ablation was successful in $64 \%$ of patients and additional pulmonary vein lines were required in 10 more patients, for a total $\mathrm{AF}$ termination in $77 \%$. Of the patients with terminated AF, however, $49 \%$ had at least 1 episode of atrial tachycardia requiring antiarrhythmic drugs, cardioversion, or a repeat procedure. Rostock and colleagues ${ }^{7}$ adopted a sequential lesion approach for persistent $\mathrm{AF}$ termination. First a pulmonary vein isolation was performed, then defragmentation of the left atrium, coronary sinus, and right atrium. Of 88 patients, 68 patients $(77 \%)$ had AF termination, the left atrium in $37(55 \%)$ and the right atrium in $18(26 \%)$. Fifty-four patients required at least 1 redo ablation. A total of 154 redo ablations were performed. In the more invasive world of cardiac surgery, these would be unacceptable surgical lesion sets for this disease with disappointing results.

In persistent $\mathrm{AF}$, it appears to matter to have a complete lesion set addressing all 7 atrial regions. On the basis of the persistent AF mapping results, Ehrlich and colleagues ${ }^{1}$ performed either a Cox-maze III or IV on the 10 patients included in the study. The surgical literature bears out that best results for termination of AF are achieved when the surgeon performs a biatrial lesion set. The number of rotors identified in the study patients add data as to why this is true. In a meta-analysis of 5 studies comparing a biatrial maze lesion set with left atrial maze lesions, Phan and coworkers ${ }^{8}$ reported freedoms from AF at 1 year in the 326 patients in the biatrial group versus the 385 patients in the left atrial group to be $78 \%$ and $71 \%$, respectively. In a large single-institution study, Kim and colleagues ${ }^{9}$ reported on 199 patients undergoing a biatrial lesion set compared with 85 patients with a left atrial lesion set alone. All had associated mitral valve disease. The 2 -year cumulative incidences of AF were $14 \%$ in the biatrial group and $26 \%$ in the left atrial group.

In fact, it is pretty clear that the closer the surgeon gets to performing a pure cut-and-sew Cox-maze III operation, the better is the freedom from AF. In one of the early comparisons of 56 patients undergoing the Cox-maze IV lesion set primarily with radiofrequency ablation for linear lesions with 56 matched patients undergoing a cut-and-sew Coxmaze III operation, Stulak and associates ${ }^{10}$ reported freedoms from AF at 15 months of $61 \%$ and $91 \%$, respectively. And in a 20-year look at the Mayo experience ${ }^{11}$ comparing various lesion sets and ablation techniques with an $80 \%$ follow-up of rhythm data (891 of 1115 patients), at every time point the cut-and-sew Cox-maze III procedure was superior to the Cox-maze IV and various other lesion sets. At 5 years, the freedom from AF without antiarrhythmic drugs was $80 \%$ for the cut-and-sew Cox-maze III procedure, compared with $61 \%$ for other procedures, including the Cox-maze III lesion set performed with alternative energy sources. In a recent single-surgeon randomized prospective series ${ }^{12}$ of 130 patients with rheumatic mitral disease comparing a cut-and-sew Cox-maze procedure III to no maze, there was a $90 \%$ freedom from AF in the Coxmaze III group. There was a significant survival advantage at 1 year of $94 \%$ versus $86 \%$ as result of stroke and anticoagulation problems in the no maze group. This was despite oversewing of the left atrial appendage in the no maze groups. These results are no small wonder in light of these data from Ehrlich and colleagues ${ }^{1}$ documenting the complexity of drivers in patients with persistent AF. The likelihood of transmurality is $100 \%$ with a cut-and-sew approach, and the other well-documented driver of persistent AF, left atrial size, is significantly reduced by sewing up the pulmonary vein-encircling incision. The Cox-maze III operation as originally described by James L. Cox and his group $^{13}$ remains appropriate for these patients with persistent AF.

\section{References}

1. Ehrlich MP, Laufer G, Coti I, Peter M, Andreas M, Stix G, et al. Noninvasive mapping before surgical ablation for persistent, long-standing atrial fibrillation. J Thorac Cardiovasc Surg. 2019;157:248-56.

2. Shah AJ, Hocini M, Pascale P, Roten L, Komatsu Y, Daly M, et al. Body surface electrocardiographic mapping for non-invasive identification of arrhythmic sources. Arrhythm Electrophysiol Rev. 2013;2:16-22.

3. Kumar S, Moore KB. The evolution of global positioning system (GPS) technology. J Sci Educ Technol. 2002;2:59-80.

4. Maddison R, Mhurchu CN. Global positioning system: a new opportunity in physical activity measurement. Int J Behav Nutr Phys Act. 2009;6:73.

5. Lim HS, Hocini M, Dubois R, Denis A, Derval N, Zellerhoff S, et al. Complexity and distribution of drivers in relation to duration of persistent atrial fibrillation. $J$ Am Coll Cardiol. 2017;69:1257-69.

6. Knecht S, Sohal M, Deisenhofer I, Albenque J, Arentz T, Neumann T, et al. Multicentre evaluation of non-invasive biatrial mapping for persistent atrial fibrillation ablation: the AFACART study. Europace. 2017;19:1302-9.

7. Rostock T, Steven D, Hoffmann B, Servatius H, Drewitz I, Sydow K, et al. Chronic atrial fibrillation is a biatrial arrhythmia data from catheter ablation of chronic atrial fibrillation aiming arrhythmia termination using a sequential ablation approach. Circ Arrhythm Electrophysiol. 2008;1:344-53.

8. Phan K, Xie A, Tsai YC, Kurar N, LaMeir M, Yan TD. Biatrial ablation vs left atrial concomitant surgical ablation for treatment of atrial fibrillation: a metaanalysis. Europace. 2015;17:38-47.

9. Kim JB, Bang JH, Yung SH, Choo SJ, Chung CH, Lee JW. Left atrial ablation versus biatrial ablation in the surgical treatment of atrial fibrillation. Ann Thorac Surg. 2011;92:1397-404; discussion 1404-5.

10. Stulak JM, Dearani JA, Sundt TM III, Daly RC, McGregor CG, Zehr KJ, et al Superiority of cut-and-sew technique for the Cox maze procedure: comparison with radiofrequency ablation. J Thorac Cardiovasc Surg. 2007; $133: 1022-7$

11. Stulak JM, Suri RM, Burkhart HM, Daly RC, Dearani JA, Greason KL, et al. Surgical ablation for atrial fibrillation for two decades: are the results of new techniques equivalent to the Cox maze III procedure? J Thorac Cardiovasc Surg. 2014; $147: 1478-87$

12. Wang $\mathrm{H}$, Han J, Wang Z, Yin Z, Li Z, Jin Y, et al. A prospective randomized trial of the cut-and-sew Maze procedure in patients undergoing surgery for the rheumatic mitral valve disease. J Thorac Cardiovasc Surg. 2018;155:608-17.

13. Cox JL, Jaquiss RD, Schuessler RB, Boineau JP. Modification of the maze procedure for atrial flutter and atrial fibrillation. II. Surgical technique of the maze III procedure. J Thorac Cardiovasc Surg. 1995;110:485-95. 